\title{
Peripheral or Central Administration of Motilin Suppresses LH Release in Female Rats: A Novel Role for Motilin
}

\author{
H. Tsukamura, ${ }^{*}$ S. Tsukahara, ${ }^{*}$ F. Maekawa,* R. Moriyama, ${ }^{*}$ B. A. S. Reyes, ${ }^{*}$ T. Sakai, $†$ Y. Niwa, ${ }^{*}$ D. L. Fostert and \\ K. -I. Maeda* \\ *Graduate School of Bioagricultural Sciences, Nagoya University, Nagoya, Japan. \\ †Laboratory of Cell Biology, Department of Regulation Biology, Faculty of Science, Saitama University, Urawa, Saitama, Japan. \\ \$Reproductive Sciences Program, Departments of Obstetrics and Gynecology and Biology, University of Michigan, Ann Arbor, MI, USA.
}

\begin{abstract}
Motilin is secreted in a clear episodic pattern during fasting or during the interdigestive phase, but feeding promptly stops this secretory pattern, and plasma concentrations of motilin decrease. We have previously determined that fasting markedly suppresses pulsatile luteinizing hormone (LH) secretion in female rats in the presence of oestrogen. In the present study, we wished to learn if motilin may mediate the fasting-induced suppression of LH secretion by determining the effects of motilin administration on LH release and on food intake. Intravenous (i.v.) injection of motilin (37 nmol/rat) suppressed LH release and significantly decreased mean LH concentrations both in ovariectomized $(\mathrm{OVX})$ and oestradiol-implanted ovariectomized $\left(\mathrm{OVX}+\mathrm{E}_{2}\right)$ rats. Food intake was significantly increased by i.v. motilin injection in OVX rats, but not in $\mathrm{OVX}+\mathrm{E}_{2}$ rats. It is likely that motilin inhibits $\mathrm{LH}$ release via inhibition of the gonadotrophin-releasing hormone ( $\mathrm{GnRH}$ )-releasing mechanism at the hypothalamic level, because motilin $(3.7 \mathrm{nmol} / \mathrm{rat})$ also suppressed $\mathrm{LH}$ secretion when centrally administered, and because LH release in i.v. motilin-treated rats increased in response to exogenous $\mathrm{GnRH}$. These results suggest that motilin may be a peripheral signal for the suppression of LH secretion through central sensors.
\end{abstract}

Malnutrition suppresses reproductive function (1-8). We have determined that $48 \mathrm{~h}$ of fasting profoundly suppresses pulsatile LH secretion in oestrogen-primed ovariectomized rats (9). Reduced glucose availability might, at least in part, mediate the fasting-induced suppression of LH secretion, because pharmacological glucoprivation by 2-deoxyglucose (2DG) suppresses pulsatile LH release in the rat $(10,11)$ and sheep (12). This suppression of LH secretion by fasting or glucoprivation is mediated by noradrenergic neurones projecting to the paraventricular nucleus in the hypothalamus to facilitate the release of corticotrophin-releasing hormone $(\mathrm{CRH})(13-16)$. The noradrenergic inputs to the paraventricular nucleus have also been suggested to induce feeding behaviour in the rat (17).

Information about glucose availability is provided to the brain not only through glucodetectors, but through other signals as well. One candidate is motilin, which is a 22-amino acid peptide found in the gastrointestinal tract, and is gener- ally considered to be a gastric motor-activity-stimulating factor (18-20). Plasma motilin concentrations increase with a typically episodic secretory pattern at approximately 100-min intervals during fasting in the dog, and feeding reduces the concentrations as well as abolishes the episodic secretory pattern (21). Among the nutrients, glucose was found to suppress motilin secretion in the dog and the human $(22,23)$. In the rat, a facilitating effect of motilin on feeding behaviour has been reported: both its peripheral administration in fasted rats and its central administration in non-fasted rats increased food intake $(24,25)$.

The potential role of motilin in the regulation of reproductive activity is not yet known. However, taken together, the above findings suggest that motilin could be one of the peripheral substances conveying information about fasting or glucoprivation to the brain to suppress $\mathrm{GnRH} / \mathrm{LH}$ secretion. The present study determined the effect of peripheral and central administration of motilin on LH secretion.

Correspondence to: Hiroko Tsukamura, Graduate School of Bioagricultural Sciences, Nagoya University, Chikusa, Nagoya 464-8601, Japan (e-mail: address: htsukamu@agr.nagoya-u.ac.jp). 


\section{Materials and methods}

\section{Animals and surgery}

Wistar-Imamichi female rats, weighing 170-200 g (7-8 months old), were used. Animals were maintained under controlled conditions (14 L: 10D, lights on at $05.00 \mathrm{~h}$, temperature at $22+2{ }^{\circ} \mathrm{C}$ ) with free access to food (Labo-MRstock, Nihon Nosan Kogyo Co., Yokohama, Japan) and water. Rats having shown at least two consecutive 4-day oestrous cycles were used. In all rats the ovaries were removed surgically (ovariectomized, OVX), and some of the females $\left(\mathrm{OVX}+\mathrm{E}_{2}\right.$ group) received oestrogen chronically by means of a subcutaneously implanted Silastic tubing (i.d., $1.5 \mathrm{~mm}$; o.d., $3.0 \mathrm{~mm}$; length, $25 \mathrm{~mm}$; Dow Corning, Midland, MI, USA) containing oestradiol-17 $\left(\mathrm{E}_{2}\right.$; Sigma, St Louis, MO, USA) dissolved in peanut oil at $20 \mu \mathrm{g} / \mathrm{ml}$. We have previously shown that rats subjected to this $\mathrm{E}_{2}$ treatment had plasma $\mathrm{E}_{2}$ concentrations at $35.8 \pm 1.2 \mathrm{pg} / \mathrm{ml}(9)$, within the range found at dioestrus in rats (5). To determine the effects of centrally delivered motilin, some $\mathrm{OVX}+\mathrm{E}_{2}$ rats were implanted with a stainless-steel guide cannula (23 gauge, Plastic Products Co., Roanoke, VA, USA) with its tip located in the third cerebral ventricle $(0.8 \mathrm{~mm}$ posterior and $7.5 \mathrm{~mm}$ ventral to bregma at the midline). They were then allowed to recover from brain surgery for 1 week before the blood sampling. All surgical procedures were performed under ether anaesthesia.

\section{Experimental protocol}

The effects of motilin were studied in freely moving conscious rats 2 weeks after OVX and $\mathrm{E}_{2}$ implantation. Synthetic porcine motilin (Peptide Institute, Osaka, Japan) was dissolved in Ringers solution (in $\mathrm{mM}, \mathrm{NaCl}, 126 ; \mathrm{KCl}, 6$; $\mathrm{Na}_{2} \mathrm{HPO}_{4}, 1 ; \mathrm{MgSO}_{4}, 0.877 ; \mathrm{NaHCO}_{3}, 22 ; \mathrm{CaCl}_{2}, 1.45 ;$ D-glucose 11.1, $\mathrm{pH} 7.4$ ) at a concentration of $37 \mathrm{nmol} / 200 \mu \mathrm{l}$ for i.v. or $3.7 \mathrm{nmol} / 2 \mu \mathrm{l}$ for i.c.v. administration. The i.c.v. dose was five times higher than the total dose previously used to induce food intake (25), and the i.v. dose used in the present study was 10 times higher than our i.c.v. dose. The motilin solution or an equal volume of the vehicle was injected after the first hour of blood sampling. Some $\mathrm{OVX}+\mathrm{E}_{2}$ rats with i.v. motilin treatment also received three i.v. injections of gonadotrophin-releasing hormone (GnRH, Sigma). GnRH $(100 \mathrm{ng} / \mathrm{kg} \mathrm{BW})$ was injected every $30 \mathrm{~min}$, starting at $30 \mathrm{~min}$ after the i.v. motilin injection. The dose was based on the findings of previous studies in which normal size LH pulses were induced by this GnRH treatment $(11,26)$. For peripheral administration, motilin and GnRH were injected through the same cannula as that from which blood was sampled. For i.c.v. administration, motilin was slowly $(1 \mu \mathrm{l} / \mathrm{min})$ administered into the third ventricle with an electrical infusion pump (Eicom, Kyoto, Japan) through an inner cannula inserted into the outer cannula. Food intake was measured by quantifying the powdered chow consumed during the 3 -h sampling period. Blood samples $(100 \mu \mathrm{l})$ were collected at 6-min intervals for $3 \mathrm{~h}$, beginning at 13:00 h, through Silastic tubing (i.d., $0.5 \mathrm{~mm}$; o.d., $1.0 \mathrm{~mm}$; Shinetsu Polymer Co., Tokyo, Japan) which was inserted into the right atrium on the previous day. An equivalent volume of red blood cells from donor rats was suspended in saline and replaced through the cannula immediately after each blood sample.

\section{Hormone assay}

Plasma LH concentrations were determined by a double-antibody radioimmunoassay with a rat LH RIA kit provided by the National Hormone and Pituitary Program (Baltimore, MD, USA) and the levels were expressed in terms of the reference preparation NIDDK rat LH RP-3. Blood samples were assayed in $50 \mu \mathrm{l}$ of plasma, and the least detectable concentration of $\mathrm{LH}$ was $0.156 \mathrm{ng} / \mathrm{ml}$. The intra- and interassay coefficients of variation were $4.2 \%$ and $11.4 \%$ at the levels of $3.3 \mathrm{ng} / \mathrm{ml}$ and $1.5 \mathrm{ng} / \mathrm{ml}$, respectively.

\section{Statistical analysis}

Mean plasma LH concentrations in the pre and postinjection periods were calculated for individuals and then for each group. Statistical differences in mean LH concentrations between pre and postinjection in each group and in food intake between vehicle-and motilin-injected groups were determined by Student's paired $t$-test.

\section{Results}

Effect of i.v. administration of motilin on LH secretion and food intake

Figure 1A,B shows representative profiles of plasma LH concentrations in $\mathrm{OVX}$ and in $\mathrm{OVX}+\mathrm{E}_{2}$ rats injected i.v. with
(A)

(c)

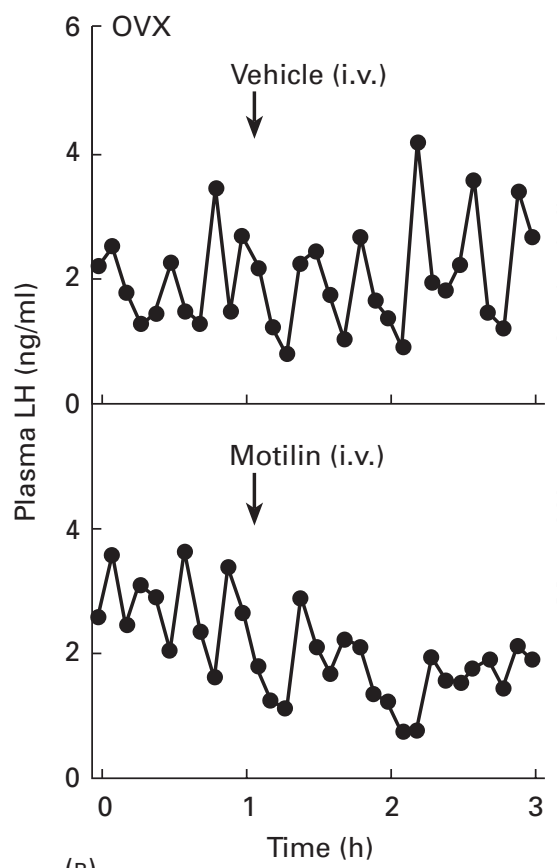

(B)

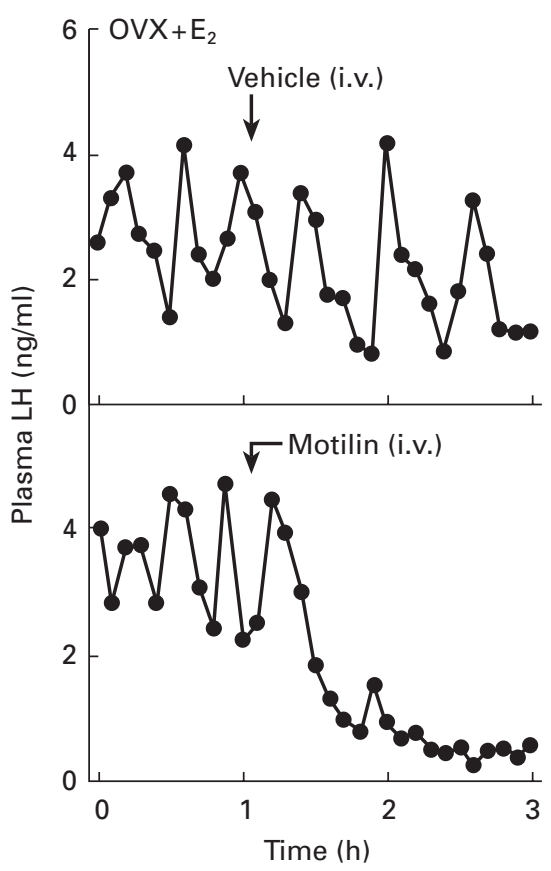

(D)

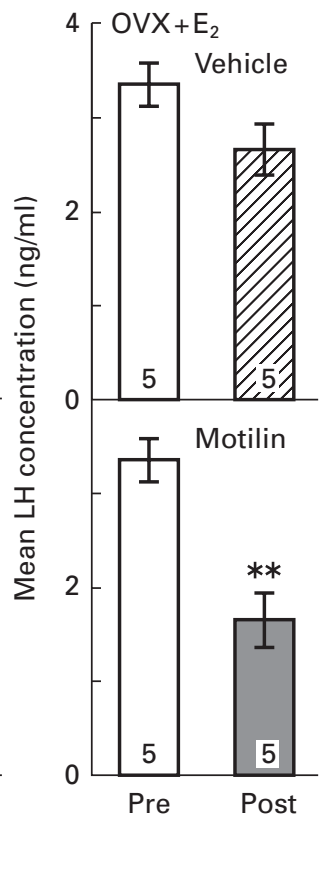

Fig. 1. Effects of i.v. injection of motilin $(37 \mathrm{nmol} / 200 \mu \mathrm{l})$ on $\mathrm{LH}$ secretion in ovariectomized (OVX) and oestradiol-implanted OVX $\left(\mathrm{OVX}+\mathrm{E}_{2}\right)$ rats. $(\mathrm{A}, \mathrm{B})$ Representative profiles of plasma LH levels in $\operatorname{OVX}(\mathrm{A})$ or $\mathrm{OVX}+\mathrm{E}_{2}$ (B) rats, which received i.v. injection (arrows) of motilin or vehicle after the first hour of blood sampling. (C,D) Mean LH concentrations (mean + SEM) at pre- and postinjection periods in OVX (C) or OVX $+\mathrm{E}_{2}$ (D) rats. Numbers in each column indicate the numbers of the animals used. ${ }^{*} \mathrm{P}<0.05 ;{ }^{*} \mathrm{P}<0.01$ vs pretreated periods (Student's $t$-test). 
motilin (37 nmol/rat) or vehicle; Fig. 1C,D present the group mean LH concentrations. In vehicle-treated controls, the mean LH concentrations in in postinjection period were not significantly different from those in preinjection periods in both OVX and OVX $+\mathrm{E}_{2}$ groups. By contrast, in i.v. motilininjected rats, the mean $\mathrm{LH}$ concentration in the postinjection period was significantly lower than in the preinjection period $\left(\mathrm{P}<0.05\right.$ for $\mathrm{OVX}$, and $\mathrm{P}<0.01$ for $\mathrm{OVX}+\mathrm{E}_{2}$ groups, Student's paired $t$-test).

Food intake in the i.v. motilin-injected OVX group was significantly higher $(\mathrm{P}<0.01$, Student's $t$-test $)$ than in vehicletreated controls, but there was no significant difference within $\mathrm{OVX}+\mathrm{E}_{2}$ groups (Fig. 2).

\section{Effect of GnRH administration on LH release in i.v. motilin- injected $\mathrm{OVX}+E_{2}$ animals}

Plasma LH concentrations were decreased after i.v. motilin injection alone (Fig. 3A, top), while an abrupt increase in LH secretion occurred in response to each GnRH treatment (Fig. 3A, bottom). Overall, the mean plasma LH concentration after i.v. motilin injection was significantly $(\mathrm{P}<0.01)$ lower compared with that before the injection (Fig. 3B, top); the circulating $\mathrm{LH}$ concentration was significantly $(\mathrm{P}<0.05)$ higher in motilin-treated rats after the multiple GnRH treatments (Fig. 3B, bottom).

\section{Effect of i.c.v. administration of motilin on LH secretion}

The third ventricular injection of motilin $(3.7 \mathrm{nmol} / \mathrm{rat})$ in $\mathrm{OVX}+\mathrm{E}_{2}$ rats immediately suppressed LH secretion, while vehicle did not (Fig. 4A). Mean LH concentrations after i.c.v. motilin administration were significantly $(\mathrm{P}<0.05)$ lower than before treatment; the mean $\mathrm{LH}$ concentration after

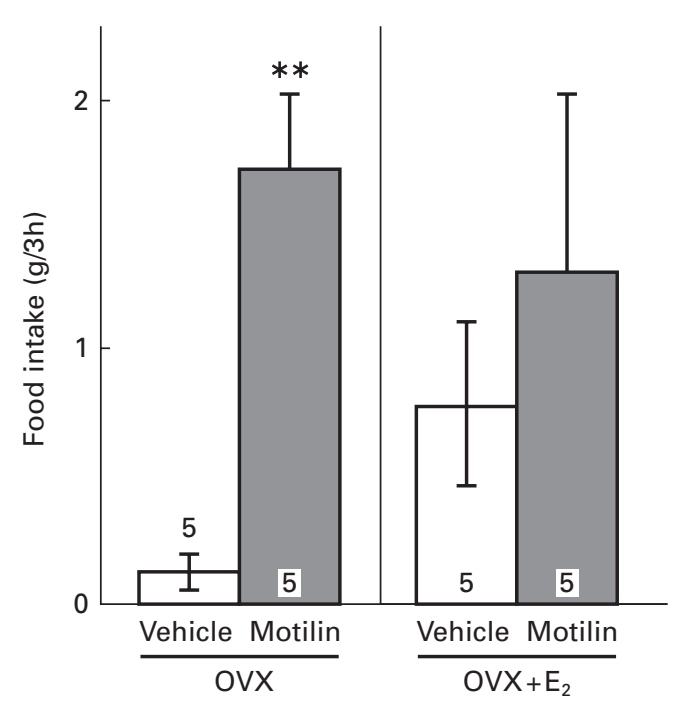

FIG. 2. Effects of i.v. injection of motilin $(37 \mathrm{nmol} / 200 \mu \mathrm{l})$ on food intake in ovariectomized (OVX) and oestradiol-implanted OVX $\left(\mathrm{OVX}+\mathrm{E}_{2}\right)$ rats. Food consumption was measured during 3-h sampling period in motilin- or vehicle-treated $\mathrm{OVX}$ or $\mathrm{OVX}+\mathrm{E}_{2}$ group. Values are mean \pm SEM. Numbers in/on each column indicate the numbers of the animals used. ${ }^{* *} \mathrm{P}<0.01$ vs vehicle-injected controls (Student's $t$-test). vehicle treatment was not significantly different to the preinjection concentration (Fig. 4B).

\section{Discussion}

The present study suggests that motilin, a gastrointestinal hormone, has an inhibitory role in the control of LH secretion. Circulating motilin appears to inhibit LH secretion by preventing the release of $\mathrm{GnRH}$, rather than by directly suppressing LH secretion at the pituitary level, because LH secretion in response to exogenous GnRH administration was not affected by peripheral administration of motilin in $\mathrm{OVX}+\mathrm{E}_{2}$ rats. In addition, we found that the i.c.v. administration of motilin immediately suppressed $\mathrm{LH}$ release and significantly decreased $\mathrm{LH}$ concentrations in $\mathrm{OVX}+\mathrm{E}_{2}$ rats. Together, these results suggest that peripheral motilin acts on the central nervous system to suppress GnRH release, and in turn LH secretion.

Perhaps motilin-induced suppression of LH secretion shares similar pathways to those mediating fasting-or glucoprivation-induced suppression. Motilin secretion from the upper digestive tract increases during fasting and decreases postprandially (21). Glucose administration reduces plasma motilin concentrations and disrupts its episodic pattern of release. Thus, motilin could be a hunger hormone secreted by the digestive tract to convey hunger information to the central nervous system (CNS), and amongst its other actions, it inhibits GnRH secretion to depress gonadal activity. However, it remains to be determined whether the doses of motilin used in the present study are physiologically and thus whether they mimic the normal effects of motilin on LH release.

The vagus nerve is thought to mediate the stimulation of motilin release during fasting; plasma motilin concentrations are increased by electrical stimulation of the vagus accompanied by an increase in gastrointestinal myoelectric activity in the $\operatorname{dog}(27)$. Atropine attenuates both vagal stimulationinduced increase in plasma motilin concentrations and episodic pattern of motilin release in fasted animals, resulting in decrease of the plasma concentrations of this peptide to baseline level (21). Our previous study revealed that fastinginduced suppression of $\mathrm{LH}$ pulses is reversed by gastric vagotomy, suggesting that vagus nerve mediates the fastinginduced suppression of LH release (28). The coincidental participation of the vagus nerve in both stimulating motilin release and suppressing $\mathrm{LH}$ release during fasting again suggests that motilin may be involved in the fasting-induced suppression of pulsatile LH release.

In the present study, food intake was significantly increased by peripheral motilin injection in OVX rats, but was not significantly affected in oestrogen-treated OVX rats. The present result is consistent with a previous result demonstrating that i.v. motilin administration did not increase food intake in gonad-intact fed rats ad lib., but enhanced food intake under fasted condition (24). Thus, gonadal steroids may have an inhibitory influence on motilin-induced feeding behaviour. Oestrogen has been suggested to have an anorectic action by acting on specific areas of the brain such as the preoptic area (29). 
(A)

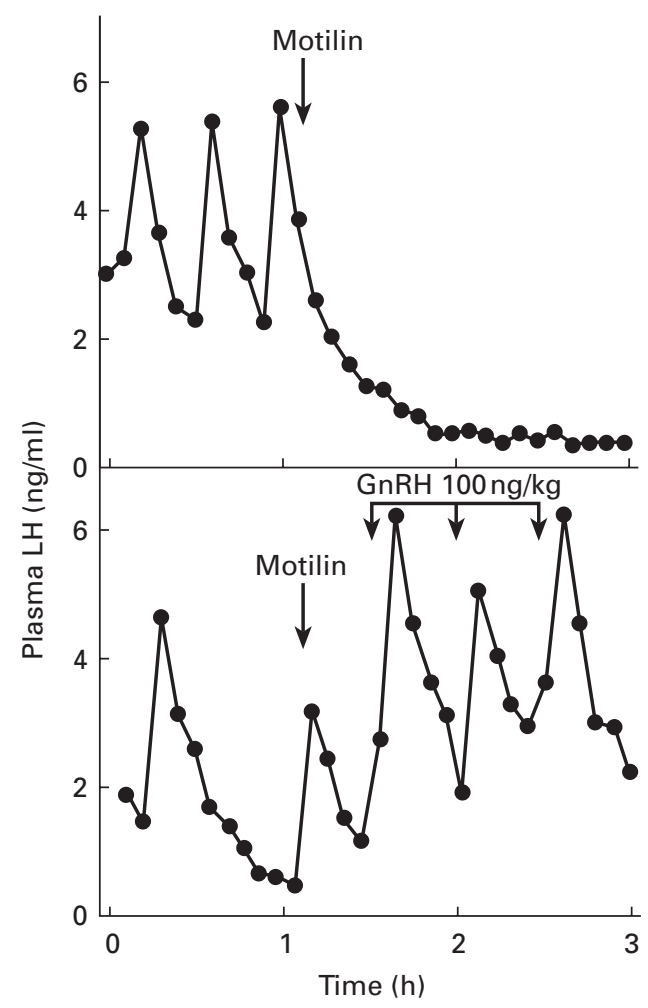

(B)

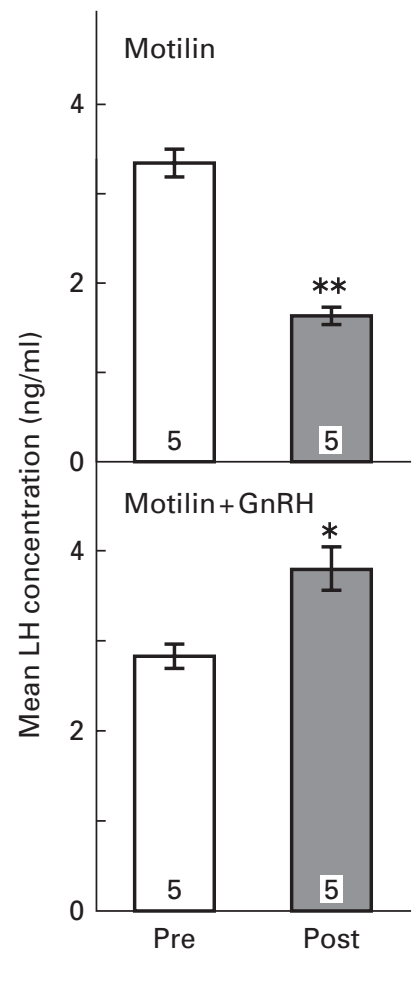

FIG. 3. Effect of GnRH administration on LH levels after i.v. injection of motilin $(37 \mathrm{nmol} / 200 \mu \mathrm{l})$ in OVX $+\mathrm{E}_{2}$ rats. (A) Representative profiles of plasma LH levels in OVX $+\mathrm{E}_{2}$ rats injected with motilin (arrows) after the first hour of blood sampling with (lower panel) or without (upper panel) GnRH treatments. GnRH (100 ng/kg BW) was i.v. injected every 30 min after the motilin treatment. (в) Mean plasma LH concentrations at pre and post-motilin injections with (lower panel) or without (upper panel) GnRH administration. Numbers in each column indicate the numbers of the animals used. ${ }^{*} \mathrm{P}<0.05 ;{ }^{*} \mathrm{P}<0.01$ vs pretreated periods (Student's $t$-test).

Because a 22 amino acid peptide may not pass easily through the blood-brain barrier, its detection by the CNS may be by the circumventricular organs, which lack or have only a weak blood-brain barrier. Of the circumventricular organs, the area postrema in particular is thought to have a motilin sensing mechanism (30). Moreover, the area postrema is considered to be an important sensor in relaying information about glucose availability to the GnRH-releasing system $(10,31)$. Another possibility is that peripheral motilin could be sensed by peripheral receptors distributed in the upper digestive tract to convey the information to the CNS through a peripheral neuronal pathway such as the vagus nerve, because the tract is abundant in motilin-binding sites which is generally considered to play a role in the induction of gastric motility $(32,33)$. Motilin might also have a role as a neuromodulator as is known for other brain-gut peptides, i.e. cholecystokinin or somatostatin. Motilin immunoreactivity has been found in several regions of the rat brain, including the hypothalamus, cerebral cortex and cerebellum (34), suggesting that motilin might be synthesized within the CNS. A binding study also suggests the existence of motilin receptors in the rabbit cerebellum (35), which is inside the blood-brain barrier. A mapping study has revealed that motilin-immunoreactive cell bodies are distributed in the mediobasal hypothalamus in colchicine-treated rats (36). In this study, a rich innervation of motilin-immunoreactive varicose fibres was found in the median eminence and organum vasculosum lamina terminalis, which are major projection sites of GnRH neurones. Furthermore, immunoreactive fibres were demonstrated in the preoptic area, where most GnRH cell bodies are located. These findings, together with the present findings, imply that motilin might also act as a neuromodulator in the hypothalamus to control GnRH release.

In conclusion, the present study suggests that motilin might be a peripheral signal to suppress reproductive function via inhibiting GnRH secretion and that central motilin receptors, at least in part, mediate this inhibition. Increased motilin release during fasting therefore may mediate the fastinginduced suppression of $\mathrm{LH}$ pulses. However, the site(s) of action for suppression of $\mathrm{GnRH}$ release by motilin remains to be clarified.

\section{Acknowledgements}

We are grateful to the National Hormone and Pituitary Program for the LH assay kit and the Imamichi Institute for Animal Reproduction for supplying the animals. The RIA and LH pulse analysis were performed at the Nagoya University Radioisotope Center and the Nagoya University Computer Center, respectively. This work was supported in part by Grants-in-Aid from the Ministry of Education, Science, Sports and Culture, Japan (nos. 11660283 and 10460131) to H.T. and K.M.; a Grant-in-Aid for International Scientific Research (Joint Research no. 09044215) to K.M.; a Research Fellowships of 

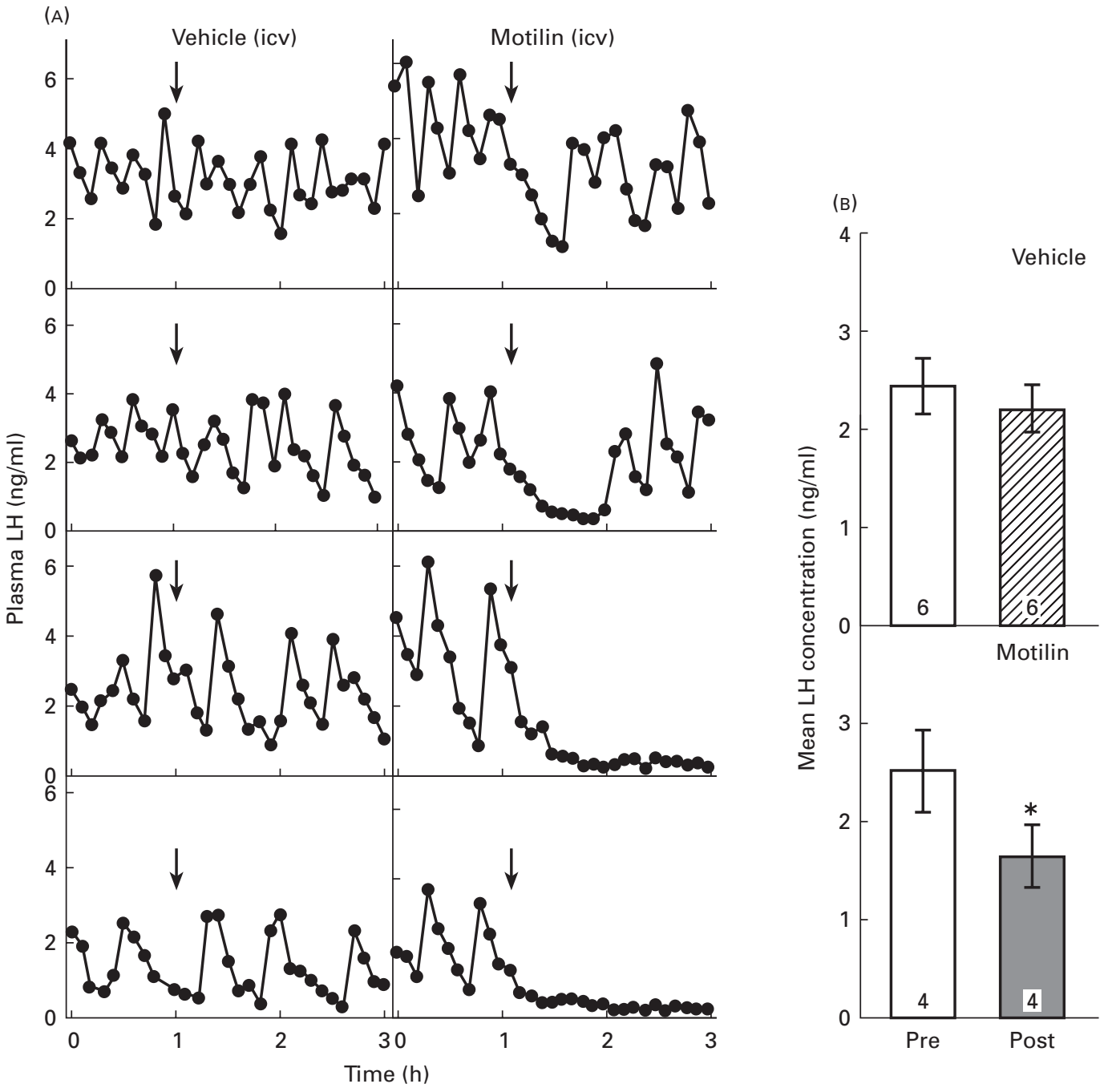

FIG. 4. Effect of i.c.v. injection of motilin $(3.7 \mathrm{nmol} / 2 \mu \mathrm{l})$ on $\mathrm{LH}$ secretion in $\mathrm{OVX}+\mathrm{E}_{2}$ rats. (A) Profiles of plasma LH levels in $\mathrm{OVX}+\mathrm{E}_{2}$ rats, which received i.c.v. injection (arrows) of motilin or vehicle after the first hour of blood sampling. (B) Mean LH (mean \pm SEM) at pre- and postinjection periods. Numbers in each column indicate the numbers of the animals used. ${ }^{*} \mathrm{P}<0.05$ vs pretreated periods (Student's $t$-test).

the Japan Society for the Promotion of Science (JSPS) for Young Scientists (no. 08003249) to S.T. from the Ministry of Education, Science, Sports and Culture, Japan; and the US-Japan Cooperative Science Program to D.L.F. from National Science Foundation (INT-9603310) and to K.M. from NSF and JSPS.

Accepted 25 October 1999

\section{References}

1 Pirke KM, Spyra B. Influence of starvation on testosterone-luteinizing hormone feedback in the rat. Acta Endocrinol 1981; 96: 413-421.

2 Warren MP. Effects of undernutrition on reproductive function in humans. Endo Rev 1983; 4: 363-377.

3 Dyer RG, Mansfield S, Corbet H, Dean DP. Fasting impairs LH secretion in female rats by activating an inhibitory opioid pathway. J Endocrinol 1985; 105: 91-97.

4 Foster DL, Olster DH. Effect of restricted nutrition on puberty in the lamb: pattern of tonic luteinizing hormone $(\mathrm{LH})$ secretion and competency of the LH surge system. Endocrinology 1985; 116: 375-381.
5 McClure TJ, Saunders J. Effects of withholding food for 0-72 h on mating, pregnancy rate and pituitary function in female rats. $J$ Reprod Fert 1985; 74: 57-64.

6 Bronson F. Effect of food manipulation on the GnRH-LH-estradiol axis of young female rats. Am J Physiol 1988; 254: R616-R621.

7 Wade GN, Schneider JE. Metabolic fuels and reproduction in female mammals. Neurosci Biobehav Rev 1992; 16: 1-38.

8 Maeda K-I, Tsukamura H. Neuroendocrine mechanism mediating fasting-induced suppression of luteinizing hormone secretion in female rats. Acta Neurobiol Exp 1996; 56: 787-796.

9 Cagampang FRA, Maeda K-I, Tsukamura H, Ohkura S, Ota K. Involvement of ovarian steroids and endogenous opioids in the fastinginduced suppression of pulsatile $\mathrm{LH}$ release in ovariectomized rats. J Endocrinol 1991; 129: 321-328.

10 Murahashi K, Bucholtz DC, Nagatani S, Tsukahara S, Tsukamura H, Foster DL, Maeda K-I. Suppression of LH pulses by restriction of glucose availability is mediated by sensors in the brain stem. Endocrinology 1996; 137: 1171-1176.

11 Nagatani S, Bucholtz DC, Murahashi K, Estacio MAC, Tsukamura H, Foster DL, Maeda K-I. Reduction of glucose availability suppresses pulsatile LH release in female and male rats. Endocrinology 1996; 137: 1166-1170. 


\section{Motilin suppresses LH release}

12 Bucholtz DC, Vidwans NM, Herbosa CG, Schillo KK, Foster DL. Metabolic interfaces between growth and reproduction. V. Pulsatile luteinizing hormone secretion is dependent on glucose availability. Endocrinology 1996; 137: 601-607.

13 Maeda K-I, Cagampang FRA, Coen CW, Tsukamura H. Involvement of the catecholaminergic input to the paraventricular nucleus and of corticotropin-releasing hormone in the fasting-induced suppression of luteinizing hormone release in female rats. Endocrinology 1994; 134: $1718-1722$.

14 Nagatani S, Tsukamura H, Murahashi K, Bucholtz DC, Foster DL, Maeda K-I. Paraventricular norepinephrine release mediates glucoprivic suppression of pulsatile LH secretion. Endocrinology 1996; 137: 3183-3186.

15 Tsukahara S, Tsukamura H, Foster DL, Maeda K-I. Effect of corticotropin-releasing hormone antagonist on oestrogen-dependent glucoprivic suppression of luteinizing hormone secretion in female rats. J Neuroendocrinol 1999; 11: 101-105.

16 Tsukamura H, Nagatani S, Cagampang FRA, Kawakami S, Maeda K-I Corticotropin-releasing hormone mediates suppression of pulsatile LH secretion induced by activation of $\alpha$-adrenergic receptors in the paraventricular nucleus in female rats. Endocrinology 1994; 134: 1460-1466.

17 Leibowitz SF. Hypothalamic paraventricular nucleus: Interaction between $\alpha 2$-noradrenergic system and circulating hormones and nutrients in relation to energy balance. Neurosci Biobehav Rev 1988; 12: 101-109.

18 Brown JC, Cook AM, Drybourgh JR. Motilin, a gastric motor activity stimulating polypeptide: the complete amino acid sequence. Can J Biochem 1973; 51: 533-537.

19 Sakai T, Satoh M, Koyama H, Iesaki K, Umahara M, Fujikura K, Itoh Z. Localization of motilin-immunopositive cells in the rat intestine by light microscopic immunocytochemistry. Peptides 1994; 15: 987-991.

20 Satoh M, Sakai T, Koyama H, Shiba Y, Itoh Z. Immunocytochemica localization of motilin-containing cells in the rabbit gastrointestinal tract. Peptides 1995; 16: 883-887.

21 Chey WY, Lee KY. Actions of motilin on gastrointestinal motility and plasma immunoreactive motilin concentration in interdigestive and postprandial states. Endocrinol Japon S R 1980; 1: 173-177.

22 Imura $\mathrm{H}$, Seino $\mathrm{Y}$, Mori K, Itoh Z, Yanaihara N. Plasma motilin levels in normal subjects and patients with diabetes mellitus and certain other diseases: fasting levels and responses to food and glucose. Endocrinol Japon SR 1980; 1: 151-155.
23 Saito S, Ogawa T, Saito H, Ishimaru K, Oshima I, Sonaka Y. Regulation of motilin secretion in the postprandial satate in man. Endocrinol Japon SR 1980; 1: 157-162.

24 Garthwaite TL. Peripheral motilin administration stimulates feeding in fasted rats. Peptides 1985; 6: 41-44.

25 Rosenfeld DJ, Garthwaite TL. Central administration of motilin stimulates feeding in rats. Physiol Behav 1987; 39: 753-756.

26 Briski KP, Sylvester PW. Acute inhibition of pituitary LH release in the male rat by the glucocorticoid decadron phosphate. Neuroendocrinology 1991; 54: 313-320.

27 Lee KY, Chang T-M, Chey WY. Effect of electrical stimulation of the vagus on plasma motilin cencentration in dog. Life Sci 1981; 29: 1093-1097.

28 Cagampang FRA, Maeda K-I, Ota K. Involvement of the gastric vagal nerve in the suppression of pulsatile LH release during acute fasting in rats. Endocrinology 1992; 130: 3003-3006.

29 Dagnault A, Richard D. Involvement of the medial preoptic area in the anorectic action of estrogens. Am J Physiol 1997; 272: R311-R317.

30 Shiba Y, Mizumoto A, Satoh M, Inui A, Itoh Z. Effect of nonpeptide motilin agonist EM523 on release of gut and pancreatic hormones in conscious dogs. Gastroenterology 1996; 110: 241-250.

31 Schneider JE, Zhu Y. Caudal brain stem plays a role in metabolic control of estrous cycles in Syrian hamsters. Brain Res 1994; 661: 70-74.

32 Sakai T, Satoh M, Hayashi H, Fujikura K, Sano I, Koyama H, Tatemoto $\mathrm{K}$, Itoh Z. Biotinyl C-terminal extended motilin as abiologically active receptor probe. Peptides 1994; 15: 257-262.

33 Sakai T, Satoh M, Sonobe K, Nakajima M, Shiba Y, Itoh Z. Autoradiographic study of motilin binding sites in the rabbit gastrointestinal tract. Regulatory Peptides 1994; 53: 249-257.

34 O'Donohue TL, Beinfeld MC, Chey WY, Chang T-M, Nilaver G, Zimmerman EA, Yajima H, Adachi H, Poth M, McDevitt RP, Jacobowitz DM. Identification, characterization and distribution of motilin immunoreactivity in the rat central nervous system. Peptides 1981; 2: 467-477.

35 Depoortere I, Peeters TL. Demonstration and characterization of motilinbinding sites in the rabbit cerebellum. Am J Physiol 1997; 272: G994-G999.

36 Jacobowitz DM, O'donohue TL, Chey WY, Chang T-M. Mapping of motilin-immunoreactive neurons of the rat brain. Peptides 1981; 2: $479-487$. 